movement probably continues during a long period of time. It may be on the whole gradual and imperceptible; but if, from time to time, the roofs of the huge vesicles, whence lava and steam have escaped, should give way, though there may be no perceptible change of level at the surface, such shocks will be generated as to convulse the area with earthquakes. We may infer that the Ischian earthquakes, though not directly connerted with the present active volcanic phenomena of the district, are the result of the former extravasation of volcanic materials, and the consequent vesicular condition of the earth's crust at the locality. But we must await the careful collection of evidence before any positive conclusion on the subject can be embraced.

\section{THE NORWEGIAN NORTH-SEA EXPEDITION}

WITH the general work of the expedition sent out by the Norwegian Government in $1876-8$ for the investigation of the physical and biological conditions of the North Atlantic, our readers have already been made familiar by communications from Dr. Mohn during the progress of the expedition. We have, moreover, already noticed one or two of the five volumes containing some of the results of the expedition. When the series of publications connected with the expedition is complete, it will form one of the most important contributions to a knowledge of the deep sea hitherto published. The present article is concerned with vols, iv. and v. of the series, containing a historical account of the expedition, a description of the apparatus used, the astronomical, magnetic, geographical, and natural history observations.

The historical account by Capt. Wille, who was in command of the vessel, the Voringen, tells us that so long ago as I874 Professors Mohn and G. O. Sars memorialised the Norwegian Government on the importance of a thorough investigation of the North Atlantic. In the memorial we find an excellent summary of what had already been done by previous expeditions, and what might be accomplished by a new one. The Norwegian Government entered heartily into the proposal for an expedition, and after taking competent advice in the matter, resolved to agree to the prayer of the memorial, and appointed Capt. Wille to make the necessary preparations. Capt. Wille at once proceeded to England to confer with Sir George Nares, and to purchase apparatus. A suitable vessel, the Voringen, was purchased, and specially fitted and equipped for the work of the expedition; very brief and elastic instructions were issued for the general conduct of the expedition, while each member of the comprebensive sciertific staff was furnished with special instructions for guidance in his work. The liberal scale on which the expedition was organised has guided the Norwegian Government in the publication of the results. These are contained in a series of large quarto volumes, beautifully printed (in Norwegian and English), and abounding with maps, coloured illustrations, and engravings. These volumes are liberally distributed among institutions and individuals in all countries, wherever indeed they are likely to be of service to science. Such liberality in a comparatively poor Government like that of Norway is in marked contrast to the conduct of the Government of the wealthiest country in the world in respect of the Challenger publications.

The general scope of the expedition was ( 1 ) to determine by soundings the contour of the sea-bed; $(2)$ the rate and direction of currents; (3) the surface-temperature of the sea; (4) to investigate the physical conditions and chemical constituents of the sea-water ; $(5)$ zoological work; (6) botanical work; (7) meteorological observations; (8) magnetical observations ; (9) whatever other observations time and place might render practical. Thus it will be seen the programme was comprehensive enough; and as the voluminous reports show, much valuable work was done in each department. Among the scientific staff on board were Prof. Mohn and G. O. Sars.

The Voringen prosecuted her work for about three months in the summers of the years $1876-7-8$. During
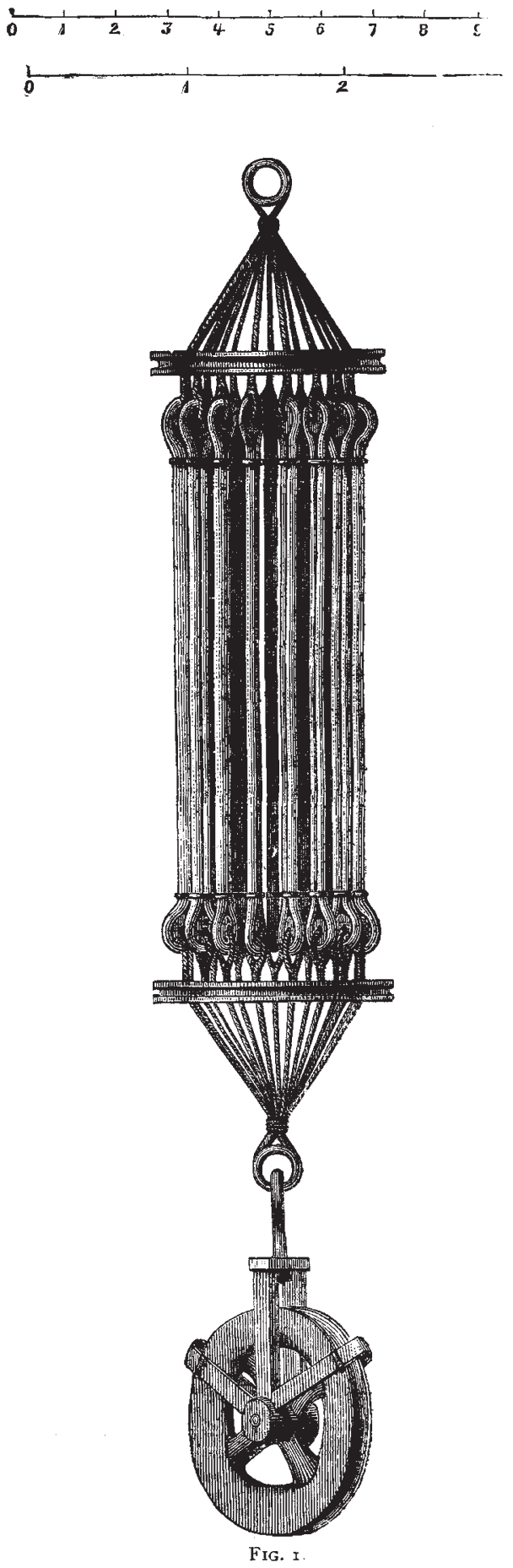

that time she made numerous sections over the region lying between the west coast of Norway and a line extending from Iceland to Spitzwergen on the one side, and between Faeroe and the north of Spitzbergen on the other; in 1878 moreover she made a circuit east and 
north from Vardoe to Bear Island. On every section stations were established for observations at very frequent intervals; off the coast of Norway these

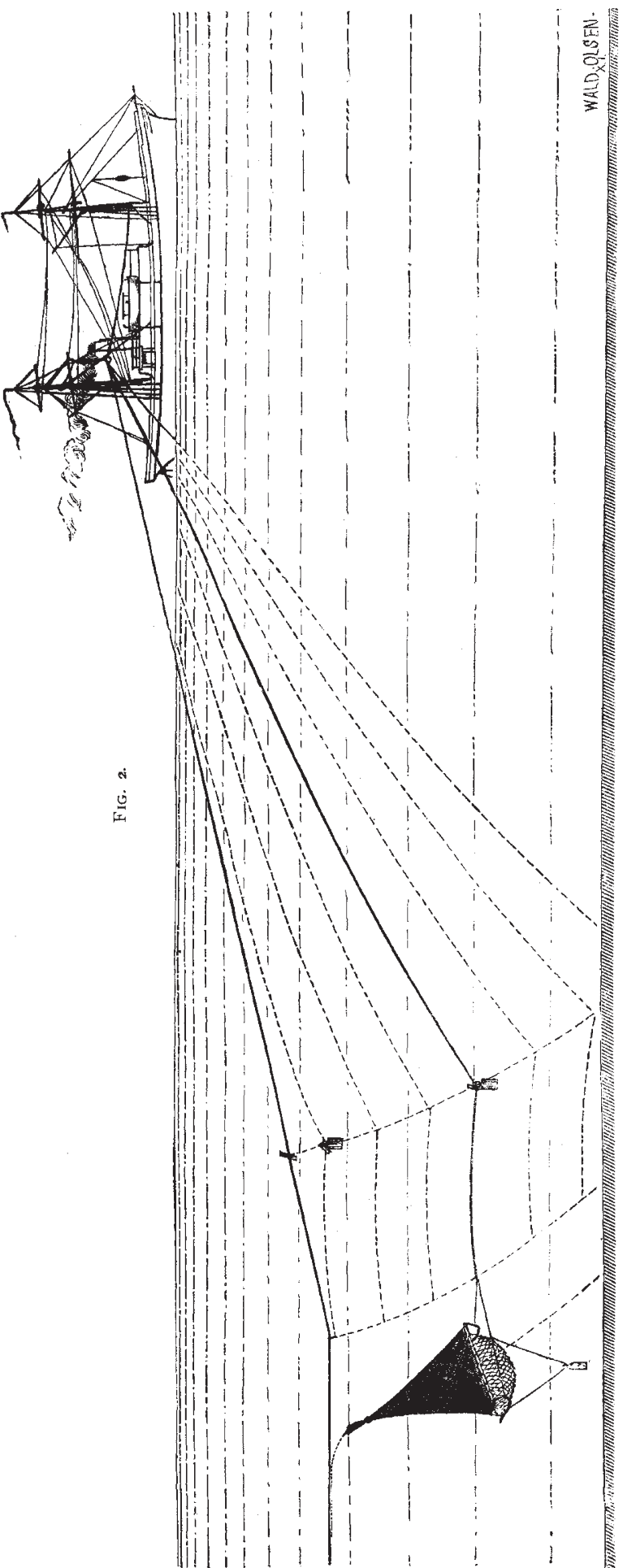

stations were as close as they could well be. The vessel itself, of 344 tons, was admirably arranged for the work, the best possible use having been made of the not too large space for disposal. The apparatus was abundant, and in its construction the experiences of previous expeditions were fully taken advantage of. We are all so familiar with the apparatus used in deep-sea work that it is unnecessary to describe it in detail. The experience of the first year led to some improvements in the arrangements of the work-room, which occupied the whole breadth of the ship; and the light and ventilation were much improved. As a specimen of the apparatus, we reproduce the illustration of the sounding accumulator (Fig. I), composed of fifteen straps. To the lower thimble is hung the cast-iron sounding-block, provided with a swivel on artificial rollers, and two hinged arms to act as fair leaders for the line. When in use, the apparatus hangs suspended from the port mainyard-arm. Its most important function is to take off the suddenness of the strain on the line when the vessel is rolling or pitching. For collecting water both from the bottom and intermediate depths, Capt. Wille devised a very ingenious water-bottle, which could hold five litres. The soundingline, 3000 fathoms, was wound on the port side of the after-deck on a large, strong reel, secured by screws to the deck. For dredging, especially, very careful preparations were made, and a variety of apparatus taken on board. Capt. Wille gives the following interesting description of their method of dredging :-

"We steamed full speed ahead, with the wind a little on our starboard bow. So soon as the vessel bad got sufficient headway, the engine was stopped, the dredge lifted by hand over the railing, and dropped into the sea. At the foremast, a man with thick leather gloves stood ready to pay out the dredge-rope, which another kept clear with a handspike as it ran out from the coil in the locker. On the dredge entering the water, the word was immediately given to veer, when the paying out commenced, slowly, however, to make sure that all was right. So soon as the diredge was clear of the propeller, the vessel again went ahead, steaming at a uniform rate of 4 knots, which the engineer was enabled to keep up by frequent reference to the water-log (see below). Meanwhile, we kept steadily veering, while taking care, by frequent holding on to the rope, that the length run out should be properly taut, and steering the course given to the ship when the dredge was put over. After paying out, according to depth, 200,300 , or 400 fathoms, we again stopped, hauled in the rope to the taffrail by means of the lizard and thimble, and fastened, below the latter, with spun-yarn, a wooden toggle to the rope. Starting again (same course and speed), we next ran out the whole length of rope deemed necessary for the operation-not less than double the depth, nay for smaller depths even more.

"The engine was now stopped, after which we hauled in the dredge-rope, as before, to the taffrail, and kept it up in a bight of rope's end. With the lizard was then made fast to the wooden thimble a weight proportioned to the depth, consisting of 3 or 4 , and for the deepest dredgings of as many as 6 , of the sinkers of the Baillie sounding-machine, weighing each 55 pounds. We now, after letting go the rope, tilted the weight overboard, which spun down along it till stopped by the wooden toggle. The shock of its arrest was distinctly perceptible to a person who had his hand on the rope.

"The vessel was now kept stationary, while the weight and the dredge were sinking. After some experience, we calculated the time required for the dredge to sink roo fathoms to be about 12 minutes. Fig. 2 will give an idea of the descent of the dredge, or rather of the trawl. The supposed depth in the diagram being 1300 fathoms, the vessel and the trawl are of course on a much larger scale. The dotted lines represent the lines of descent of the weight, the shackle, the dredge-rope, and the beam of the trawl-assuming the trawl to sink more slowly than the weight. When the weight strikes the bottom, the trawl has still some distance to travel, and the last part. of its 
line of descent will be well-nigh perpendicular. We found that, when worked in the manner described above, both trawl and dredge could as a rule without difficulty be made to reach the bottom in the right position. If the dredge or trawl descend much more slowly than the weight, it will fall vertically, with the heavy end foremost. If, on the other hand, its rate of descent be equal to or exceed that of the weights, it will, on reaching the bottom, have a horizontal component in its motionwhich is pretty sure to keep it from clogging during the ensuing operation."

In vol. v. Dr. Mohn renders account of the astronomical observations, as well as the geography and natural history of the expedition, while Capt. Wille describes the magnetic observations. The vessel was well supplied with suitable instruments for determining latitude and longi- tude, and use was made of them whenever favourable opportunities presented themselves. Observations were thus made at nine important points. The various magnetic elements were determined at eight stations on land and seven at sea.

The most interesting geographical results of the expedition were in connection with Jan Mayen, to which Dr. Mohn devotes considerable space and many fine illustrations, several of them coloured. While the expedition was in progress, Dr. Mohn sent us some account of his observations in this island, with illustrations (vol. xviii. p. 222), but of course the subject is more fully treated in the volume before us. Evidences of volcanic action were observed everywhere, and the forms of some of the old craters are very beautiful. As the main object of the expedition was deep-sea research, Dr. Mohn could not



FIG 3

give so much time to the observations of the island as he could have wished; nevertheless, by bringing together the observation; of the various members of the expedition, and comparing them with the results obtained by Scoresby and other previous observers, Dr. Mohn is able to give a very full and interesting account of this curious island, which we here quote:-

"Cut off on all sides by extensive ocean tracts from the nearest land, the Island of Jan Mayen occupies an isolated position in the Greenland Sea. Between Norway and Jan Mayen the depth reaches I 760 fathoms, towards Spitzbergen upwards of 2000 fathoms, towards Greenland upwards of 1300 fathoms, and towards Iceland upwards of rooo fathoms. The direction of the island is from N.E. by E. to S.W. by W.; it points towards Denmark Strait, and lies parallel to the volcanic line of Mount Hecla. As previously stated, Jan Mayen is built up of volcanic rocks, all of which would appear to belong to the modern group.
Hence the island is probably a later formation than are the Faeroes and Iceland, where the old volcanic rocks prevail either exclusively or in greater part. Its length slightly exceeds $7 \frac{1}{\frac{1}{2}}$ geographical miles. It consists of two large parts or divisions, a northern and a southern, connected together by a lower and narrower tract. The greatest breadth of the northern part is a little more than 2 geographical miles, that of the southern $\mathrm{I} \frac{1}{2}$ geographical miles, and the connecting tract (including the lagoon) measures at the narrowest point $I_{2} \frac{1}{2}$ English miles across $(0.4$ geographical mile). The area of the island is 7.32 geographical square miles."

Fig. 3 gives a view of the headland forming the northeast extremity of North or English Bay, the isolated rock in the distance being the Brielle Tower of the Dutch navigators.

(To be continued.) 